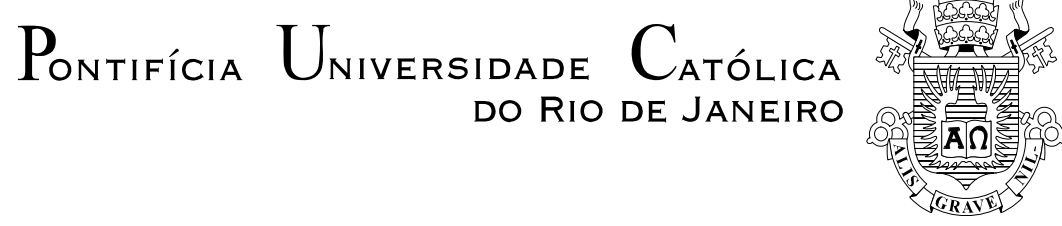

Renato Teixeira Lima

Redes Neurais Artificiais Aplicadas no Controle de Tensão de Sistemas Elétricos de Potência

\author{
Dissertação de Mestrado
}

\begin{abstract}
Dissertação apresentada como requisito parcial para obtenção do grau de Mestre pelo Programa de Pósgraduação em Engenharia Elétrica do Departamento de Engenharia Elétrica da PUC-Rio.
\end{abstract}

Orientadora: Profa. Marley Maria Bernardes Rebuzzi Vellasco

Rio de Janeiro 


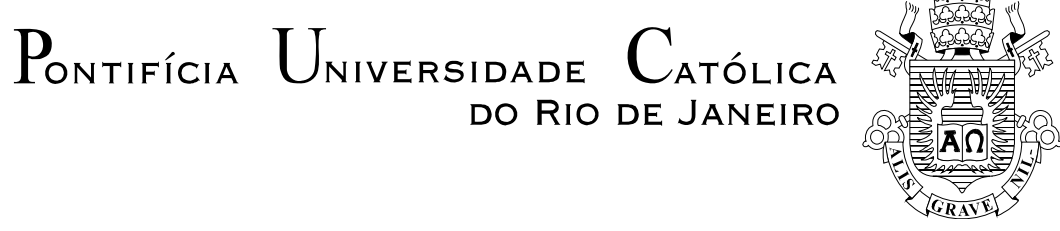

Renato Teixeira Lima

\section{Redes Neurais Artificiais Aplicadas no Controle de Tensão de Sistemas Elétricos de Potência}

Dissertação apresentada como requisito parcial para obtenção do grau de Mestre pelo Programa de PósGraduação em Engenharia Elétrica do Departamento de Engenharia Elétrica do Centro Técnico Científico da PUCRio. Aprovada pela Comissão Examinadora abaixo assinada.

Dra. Marley Maria Bernardes Rebuzzi Vellasco

Orientadora

Departamento de Engenharia Elétrica/PUC-Rio

Dr. Alexandre Pinto Alves da Silva COPPE/UFRJ

Dra. Karla Tereza Figueiredo Leite

UERJ

Dr. Carlos Roberto Hall Barbosa

Departamento de Metrologia/PUCRio

Prof. José Eugenio Leal Coordenador Setorial do Centro

Técnico Científico 
Todos os direitos reservados. É proibida a reprodução total ou parcial do trabalho sem autorização da universidade, do autor e da orientadora.

\section{Renato Teixeira Lima}

Nasceu em 01 de setembro de 1979. Obteve formação técnica em Eletrotécnica Industrial em 1999 e grau de Engenheiro Eletricista em 2005, pelo CEFET-RJ. De 1999 a 2004 trabalhou para Furnas Centrais Elétricas S.A. como Operador do Sistema Elétrico, chegando ao cargo de Operador Supervisor em 2005. Desde 2005 trabalha como Engenheiro de Sistemas de Potência para o Operador Nacional do Sistema Elétrico (ONS).

Ficha Catalográfica

\section{Lima, Renato Teixeira}

Redes neurais artificiais aplicadas no controle de tensão de sistemas elétricos de potência / Renato Teixeira Lima ; orientadora: Marley Maria Bernardes Rebuzzi Vellasco. - 2007.

99 f. ; $30 \mathrm{~cm}$

Dissertação (Mestrado em Engenharia Elétrica) Pontifícia Universidade Católica do Rio de Janeiro, Rio de Janeiro, 2007.

Inclui bibliografia

1. Engenharia elétrica - Teses. 2. Controle de tensão. 3. Redes neurais. 4. Sistema elétrico de potência. I. Vellasco, Marley Maria Bernardes Rebuzzi. II. Pontifícia Universidade Católica do Rio de Janeiro. Departamento de Engenharia Elétrica. III. Título. 


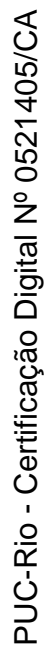

À minha família e aos meus amigos. 


\section{Agradecimentos}

À minha mãe e ao meu avô pelo carinho e educação.

Às minhas avós pelo carinho.

Ao meu irmão pelo companheirismo.

À Fernanda pelo carinho e compreensão.

Aos amigos Aline, Armando, Bruno, Maurício, Renato, Anderson, Kaeby e Daniel que sabem como é importante a amizade.

A todos os amigos do COSR-SE do ONS que contribuíram direta e indiretamente com este trabalho.

Especialmente aos amigos da Pós-operação do COSR-SE.

Luiz Cláudio e Arthur Santa Rosa, muito obrigado pela co-orientação.

À Marley pela ótima orientação, sempre disponível quando necessário.

Aos professores.

A todos que torcem por mim. 


\section{Resumo}

Lima, Renato Teixeira; Vellasco, Marley Maria Bernardes Rebuzzi (Orientadora). Redes Neurais Artificiais Aplicadas no Controle de Tensão de Sistemas Elétricos de Potência. Rio de Janeiro, 2007. 99p. Dissertação de Mestrado - Departamento de Engenharia Elétrica, Pontifícia Universidade Católica do Rio de Janeiro.

O controle das tensões dos diversos barramentos de um sistema elétrico de potência tem como objetivo garantir a qualidade da energia fornecida aos consumidores. As tensões devem respeitar níveis regulamentados pelo governo. Atualmente, no Sistema Elétrico de Potência (SEP) brasileiro, a tarefa do controle de tensão, realizada pelos operadores de tempo real, se baseia nos valores e tendências de diversas variáveis (tensões, potências reativas e ativas, sensibilidade dos equipamentos, dentre outras). Para a formação de um operador nessa tarefa são necessários de um a dois anos, tempo que poderia ser reduzido caso um sistema de apoio à decisão dedicado ao problema de controle de tensão estivesse à disposição durante o treinamento. Entretanto, em virtude do grande número de grandezas a serem analisadas e de suas não linearidades, é necessário uma ferramenta automática de apoio à decisão que seja capaz de tratar intrinsecamente relações não lineares. Deste modo, neste trabalho optou-se por desenvolver um sistema baseado em Redes Neurais Artificiais (RNA) para a confecção do sistema sugerido, com o objetivo de indicar a necessidade de realizar ações de controle de tensão utilizando-se dos recursos ou equipamentos disponíveis. O sistema desenvolvido é composto de três módulos: Pré-processamento; Análise e Classificação do evento; e Pós-processamento. Tal sistema serve para sugerir a manobra de equipamentos mais adequada para o controle de tensão. No estudo de caso, o sistema proposto foi avaliado nos equipamentos de controle de tensão (reatores, capacitores e tapes) constantes no Sistema de Transmissão em 765 kV, responsável pela interligação dos sistemas Sul e Sudeste do Brasil. Utilizando dados obtidos do sistema de aquisição em tempo real, diferentes configurações de RNAs foram testadas. Os melhores resultados foram obtidos com uma estrutura de duas redes neurais por equipamento a ser controlado, apresentando, em média, $80 \%$ de acerto em relação às manobras realizadas em tempo real. Em virtude da complexidade do problema, os resultados foram considerados mais do que satisfatórios, indicando a aplicabilidade desta técnica para a realização do sistema desejado.

\section{Palavras-chave}

Controle de tensão, redes neurais, sistema elétrico de potência. 


\section{Abstract}

Lima, Renato Teixeira; Vellasco, Marley Maria Bernardes Rebuzzi (Advisor). Artificial Neural Neyworks in the Voltage Control of Electrical Power Systems. Rio de Janeiro, 2007. 99p. MSc. Dissertation Departamento de Engenharia Elétrica, Pontifícia Universidade Católica do Rio de Janeiro.

The main objective of the voltage control in Electrical Power System (EPS) is to guarantee the quality of the energy supplied to consumers. The voltage must respect government regulated levels. Currently, on the Brazilian EPS, the voltage control task is carried out by system operators based on diverse information, such as current values, and trends of electric variables (voltages, reactive and active powers, their sensitivities in the control devices performance, amongst others). To fully train a operator in this task it is necessary one or two years, period that could be greatly reduced if a decision support system was available during the operator's training. However, due to the great number of variables that must be analyzed and their nonlinearity, an automatic decision support tool, capable to treat nonlinear relations, is necessary. Therefore, this work proposes a system based on Artificial Neural Networks (ANN), with the objective to identify the necessity or not to use the voltage control resources in the EPS. The developed system is composed of three modules: Pre-processing; Event Analysis and Classification; and Post-processing. Such decision support system suggests the most adequate equipment maneuver in the voltage control task. In the case study, the proposed system was evaluated using the available voltage control equipments (reactors, capacitors and transformer taps) in the $765 \mathrm{kV}$ Transmission System, main responsible trunk for the interconnection of South and Southeastern Brazilian systems. Using real time data, different ANN configurations have been tested. The best results were obtained with a structure composed of two neural networks, for each controlled equipment, presenting, in average, 80\% accuracy in relation to maneuvers occurred in real time. Due to the problem complexity, the results were considered more than satisfactory, indicating the applicability of this technique for the development of the desired system.

\section{Keywords}

Voltage control, neural newtroks, electrical power system. 


\section{Sumário}

1 Introdução 13

1.1. Motivação 13

$\begin{array}{lr}\text { 1.2. Objetivos } & 17\end{array}$

$\begin{array}{ll}\text { 1.3. Descrição do Trabalho } & 17\end{array}$

1.4. Organização do Trabalho 18

2 Controle de Tensão em Sistemas Elétricos de Potência 19

2.1. Controle de Tensão Mediante Ajuste da Excitação das Unidades Geradoras

22

2.2. Controle de Tensão por Tapes de Transformadores 26

2.3. Controle de Tensão por Banco de Capacitores e de Reatores em

Paralelo

29

2.4. Controle de Tensão dos Terminais de Longas Linhas de

Transmissão

32

2.5. Exemplo Real de Controle de Tensão 35

2.6. Controle Coordenado de Tensão 37

2.7. Aplicações de RNA nos SEPs 41

2.7.1. Previsão de Carga 43

2.7.2. Diagnóstico de Falhas 43

2.7.3. Planejamento Operacional 44

2.7.4. Análise de Segurança 44

3 Sistema de Apoio à Decisão para o Controle de Tensão (SADECT) Baseado em Redes Neurais

3.1. Dados de Entrada e Crítica 46

3.2. Pré-processamento 51

3.3. Classificação dos eventos 53

3.3.1. Modelo RNA CENTRAL

3.3.2. Modelo RNA ÚNICA

3.3.3. Modelo RNA DUPLA 56

3.4. Pós-processamento 58

4 Estudo de Caso $\quad 61$

4.1. Base de Dados $\quad 64$

4.2. Pré-processamento $\quad 71$

4.2.1. Pré-processamento dos Dados de Entrada $\quad 71$

4.2.2. Pré-processamento dos Dados de Saída 78

4.3. Classificação dos eventos 80

4.3.1. Modelo RNA CENTRAL $\quad 81$

4.3.2. Modelo RNA ÚNICA 86

4.3.3. Modelo RNA DUPLA

4.3.4. Discussão dos Resultados 92 
5 Conclusões e Trabalhos Futuros

93

5.1. Conclusões

93

5.2. Trabalho Futuros

Referências bibliográficas 


\section{Lista de figuras}

Figura 1 - Curva de carga no Brasil em um dia útil 15

Figura 2 - Triângulo de potências $\quad 21$

Figura 3 - SEP exemplo 23

Figura 4 - Controle de tensão pelas unidades geradoras 25

Figura 5 - Desequilíbrio de potência reativa entre unidades geradoras 26

Figura 6 - Controle de tensão pelos tapes de transformadores 28

Figura 7 - Desequilíbrio de potência reativa entre os transformadores 29

Figura 8 - Entrada de $20 \mathrm{MW}$ de carga no barramento $F \quad 31$

Figura 9 - Manobra para ligar o banco de capacitores de 15 Mvar 31

Figura 10 - Elevação da tensão por "Efeito Ferranti" 33

Figura 11 - Mudança de período de carga 35

Figura 12 - Correção da tensão no período de carga pesada 36

Figura 13 - Modelo do controle coordenado de tensão 39

Figura 14 - Percentual do número de publicações para cada aplicação apresentada em [HAQUE, 2005] 43

Figura 15 - Exemplo de RNA 46

Figura 16 - Módulos do SADECT 47

Figura 17 - SEP exemplo $\quad 48$

Figura 18 - Modelo RNA CENTRAL para os ECT do SEP exemplo 55

Figura 19 - Modelo RNA ÚNICA para os ECT do SEP exemplo 56

Figura 20 - Modelo RNA DUPLA para os ECT do SEP exemplo 57

Figura 21 - SEP exemplo após a entrada de $20 \mathrm{MW}$ de carga 59

Figura 22 - Interligação Sul/Sudeste 61

Figura 23 - Fluxograma da obtenção de dados de entrada do histórico 65

Figura 24 - Interligação Sul/Sudeste e ECTs do SADECT 70

Figura 25 - Todos os valores das tensões, normalizados, referentes aos eventos do agrupamento $B R(1$ e 2$)$ da STIV

Figura 26 - Valores das tensões STIA 765 kV e ITAIPU 500 kV, normalizados, referentes aos eventos do BR(1 e 2) de STIV 76

Figura 27 - Todos os valores das tensões, normalizados de forma ajustada, referentes aos eventos do agrupamento BR(1 e 2) da STIV 77 Figura 28 - Valores encontrados na saídas Não manobrar da primeira RNA do modelo RNA CENTRAL

Figura 29 - Valores normalizados da tensão STIV 765 kV - VT ordenados por saída da primeira RNA do modelo RNA CENTRAL

Figura 30 - Valores normalizados de tensão ordenados por saída da primeira RNA do modelo RNA CENTRAL 


\section{Lista de tabelas}

Tabela 1 - Faixas de tensão para o SEP exemplo 24

Tabela 2 - Quantidade de artigos publicados utilizando técnicas de

RNA entre os períodos de 1990-1996 e 2000-2005. 42

Tabela 3 - ECT e respectivas manobras 49

Tabela 4 - Dados de entradas para o BC $\quad 50$

Tabela 5 - Valores máximos e mínimos das variáveis de entrada 52

Tabela 6 - Dados de entrada do exemplo da Tabela 4 transformados 52

Tabela 7 - ECTs e respectivos eventos 53

Tabela 8 - Eventos e Classes $\quad 54$

Tabela 9 - Exemplos de saídas para o modelo RNA CENTRAL $\quad 59$

Tabela 10 - Exemplos de saídas para o modelo RNA ÚNICA 60

Tabela 11 - Exemplos de saídas para o modelo RNA DUPLA 60

Tabela 12 - Variáveis de entrada do SADECT para o estudo de caso 64

Tabela 13 - Quantidade total de manobras por equipamento 66

Tabela 14 - Amostra das manobras do Tape STTP 765/500 kV 67

Tabela 15 - Amostra de eventos dos tapes dos transformadores

$765 / 500 \mathrm{kV}$ da STTP

68

Tabela 16 - Tensões referentes à amostra de eventos dos tapes dos transformadores 765/500 kV da STTP

68

Tabela 17 - Estado operativo dos equipamentos referentes à amostra de eventos dos tapes dos transformadores 765/500 kV da STTP 69

Tabela 18 - Quantidade total de eventos por equipamento 70

Tabela 19 - Agrupamento dos estados operativos dos equipamentos

referentes à amostra de eventos dos tapes dos transformadores

765/500 kV da STTP

72

Tabela 20 - Valores máximos e mínimos para os agrupamento dos estados operativos dos equipamentos

Tabela 21 - Normalização dos valores dos agrupamento dos estados operativos dos equipamentos referentes à amostra de eventos dos tapes dos transformadores $765 / 500 \mathrm{kV}$ da STTP

Tabela 22 - Valores máximos e mínimos para as tensões e hora

Tabela 23 - Valores normalizados para as tensões e hora da amostra de eventos dos tapes dos transformadores 765/500 kV da STTP

Tabela 24 - Valores normalizados para as tensões e hora da amostra de eventos dos tapes dos transformadores 765/500 kV da STTP

Tabela 25 - Novas variáveis de entrada do SADECT para o estudo de caso, após o pré-processamento dos dados de entrada

Tabela 26 - Eventos e Classes

73

Tabela 27 - Pré-processamento da amostra de eventos dos tapes dos transformadores 765/500 kV da STTP 
Tabela 28 - Eventos possíveis para a primeira RNA do modelo RNA CENTRAL

Tabela 29 - Classificação dos eventos possíveis para a primeira RNA do modelo RNA CENTRAL

Tabela 30 - Resultados dos testes da primeira RNA do modelo RNA CENTRAL

Tabela 31 - Eventos possíveis para a RNA referente ao BR(1 e 2) de STIV do modelo RNA ÚNICA

Tabela 32 - Classificação dos eventos possíveis para a RNA referente ao BR(1 e 2) de STIV do modelo RNA ÚNICA

Tabela 33 - Testes da Rede Neural para o BR de STIV

87

Tabela 34 - Classificação dos eventos possíveis para as RNAs referentes ao BR(1 e 2) de STIV do modelo RNA DUPLA 88

Tabela 35 - Resultados dos testes das RNA-1 e RNA-2 para o

BR(1 e2) da STIV

Tabela 36 - Resultados dos testes das RNA-1 e RNA-2 para o BC da STTP

Tabela 37 - Resultados dos testes das RNA-1 e RNA-2 para o BR(5) da STTP

Tabela 38 - Resultados dos testes das RNA-1 e RNA-2 para o T3 da STTP

Tabela 39 - Resultados dos testes das RNA-1 e RNA-2 para o T2 da STTP

Tabela 40 - Resumo dos resultados dos testes das RNAs para o modelo RNA DUPLA

Tabela 41 - Resumo das RNAs do modelo RNA DUPLA 